\title{
A ADMINISTRAÇÃO DO STRESS NA PREVENÇÃO DE CONFLITOS NAS ORGANIZAÇÕES
}

Jerson Joaquim da Silva

Universidade do Oeste Paulista - UNOESTE, curso de Administração, Presidente Prudente, SP. E-mail: jersonjsilva@hotmail.com

\section{INTRODUÇÃO}

Percebe-se que o stress coloca algumas adversidades em questão do relacionamento entre colaboradores, e traz para as organizações um relacionamento que gera conflitos e afeta diretamente a produtividade da mesma. O relacionamento quando não funciona de forma afetiva, afeta o clima organizacional, incidindo, diretamente, na produtividade da empresa, podendo gerar maior cobrança sobre os colaboradores, impactando para os líderes de equipes problemas que podem afetar sua gestão.

A compreensão básica do stress, seus sinais, sua fonte e seus sintomas aumentarão as chances de se fazer a escolha apropriada das soluções e aplicá-las na vida pessoal e profissional. Este tipo de atitude poderá ajudar a melhorar a saúde e a qualidade de vida de todos que laboram no ambiente de trabalho.

Diante desses fatores que se encontram no ambiente de trabalho, é necessário que se observe atentamente como esses agentes se manifestam, sabendo que dentro de uma organização trabalham pessoas com diferentes tipos de personalidade, de percepções, de opiniões, e atitudes divergentes.

Pressupõe-se que o emocional do ser humano é variável de acordo com seu dia-a-dia, podendo determinar o tipo de relacionamento que irá influenciar no desenvolvimento organizacional, e nesse sentido, os colaboradores por terem uma vida fora da empresa que pode alterar seu foco profissional, como em muitos casos preocupações, conflitos familiares etc.,podem apresentar diversos tipos de relacionamentos, podendo influenciar na geração de conflitos.

Pesquisas mostram que o ser humano, em seu ambiente de trabalho, desenvolve várias atitudes em função de seu bem-estar, focando no seu crescimento e desenvolvimento profissional.

Muitos colaboradores, por algum sentimento de querer crescer rapidamente dentro das organizações, podem focalizar seu trabalho como um todo e a cada etapa alcançada, atingindo seus objetivos sem detrimento a sua vida pessoal, buscando a qualquer preço o processo de crescimento dentro da organização.

Justifica-se que esta pesquisa está disposta a mostrar que o relacionamento entre colaboradores é uma das bases que traz maior produtividade para a organização, um bom relacionamento facilita o trabalho dos gestores, equilibra o nível de stress e filtra a sua parte positiva de alerta, evita conflitos e resistência a novas mudanças e coloca maior motivação dentro das equipes.

E como objetivo geral analisar os aspectos positivos do stress no ambiente de trabalho. Tem como objetivos específicos: desenvolver o controle do stress a fim de desenvolver a resiliência; entender quais são os principais causadores do stress nas organizações e qual suas consequências e verificar como o stress pode ser usado na administração de conflitos.

\section{METODOLOGIA}


Como metodologia, foi adotada a abordagem qualitativa por se tratar de uma pesquisa bibliográfica. E como pesquisa bibliográfica a mesma teve caráter exploratório, pois na medida em que ia se explorando o tema se constitui também de pesquisa descritiva. Iniciou-se no mês de agosto de 2016 e concluída em abril de 2017, quando os textos foram terminados. Fez-se uma síntese conclusiva de tudo que foi produzido apontando os pontos mais relevantes dos pensamentos dos autores que se constituíram em novos conhecimentos para este trabalho.

\section{RESULTADOS}

A pesquisa revelou que o stress é a adaptação que nosso organismo na busca à determinada situação ou mudança, e que promove uma nova forma de lidar com algo que está sendo feito em benefício da organização ou melhoria de determinado setor.

Pode-se entender que o stress é algo inevitável na vida e no trabalho e que por meio dele, possa-se extrair qualidades ou também deixar de produzir e fazer com que acontecem mais conflitos com maiores frequências.

"O homem contemporâneo se defronta com o paradoxo do stress. Ele e aparte essencial de nossas vidas nos dando ímpeto, vitalidade, motivação e progresso. Por outro lado, ele também e a raiz de uma infinidade de problemas econômicos e sociais". (SILVA, 2004, p.12).

Percebe-se pela citação do autor, que o stress é algo inevitável na vida do ser humano, fazendo parte do dia-a-dia do trabalhador e traz benefícios e malefícios; algumas pessoas quando filtra bem determinada situação equilibra bem seu nível de stress ao ponto de alerta, o colaborador se torna mais produtivo, criativo, atento etc. $O$ stress pode causar também diversos problemas de saúde, ao ponto de causar afastamento, a sensação de medo, desconforto, irritação são alguns sentimentos que o colaborador apresenta ter quando seu nível de stress aparenta ser muito alto.

Pressupõe-se que o stress é necessário saber o significado e o que ele pode causar em nosso cotidiano.

O termo stress, na forma que tem sido utilizado, bem da física e, nesse campo de conhecimento, tem o sentido do grau de deformidade que uma estrutura sofre quando e submetida a um esforço. Assim ao pressionar com a ponta de um lápis a borracha que esta a minha frente, pode ver que se formara uma pequena depressão. Isso acontece com a grande maioria das matérias, sendo a deformidade de maior ou menor grau, conforme a dureza deles e o esforço a que são submetidos. Hans Selye utilizou esse termo para denominar o conjunto de reações que um organismo desenvolve ao ser submetido a uma situação que exige esforço e adaptação. (FRANCA \& RODRIGUES, 2002, p.27).

Segundo Arroba e James (1988), cada pessoa necessita de um nível equilibrado de stress em seu organismo, quando os colaboradores organizacionais afastam desse nível equilibrado ocorre sérios problemas como de saúde e conflitos internos, o mesmo acontece com a organização se não haver um bom nível de stress, suas consequências se tornarão um ambiente monótono e sonolento; caso contrário, o excesso do nível de stress ocasiona conflitos, deixando o ambiente totalmente tenso e impedirá um desempenho eficaz e eficiente.

Considera-se que o stress é algo necessário, mas em nível moderado pode trazer benefícios quando souber usá-lo. O stress dá a oportunidade de o trabalhador ser mais criativo e atento até um determinado ponto, assim que ultrapassar esse ponto pode trazer sérias consequências à saúde do trabalhador. 
"Stress é, portanto, uma resposta de adaptação do nosso organismo antes de qualquer coisa. É um mecanismo inato de auto prevenção". (SILVA, 2004, p.14).

Essa citação dá o sentido claro que o stress é uma reação do organismo na presença de situações de perigo, o corpo reage de tal forma que o trabalhador fica mais alerta e atento para evitar situações inesperadas. Com o stress em bom nível, pode-se obter proveito disso; caso contrário, pode-se retrair esses sentimentos e gerar algo excessivo como: medo, insegurança, frustração, irritação etc.

Para definir o stress pode-se dizer que e uma reação que temos diante de algo, bom ou mau, que nos obrigue a fazer um esforço maior do que o usual para nos adaptarmos ao que está acontecendo, seja no mundo lá fora seja em nossa mente. (LIPP, 2005, p.68.)

Portanto, o stress é algo visto como uma reação diante de certas mudanças, algumas causas que agravam o stress no ser humano são mudanças relativas e inesperadas, sabendo filtrar esses acontecimentos e pode-se tirar proveito das mesmas o colaborador desenvolve um comportamento resiliente que consegue filtrar e extrair somente o necessário para uma boa relação e administrar bem os conflitos.

Segundo Silva (2004), o stress não e mal em si, como também não é uma doença ou uma invenção do mundo moderno, o stress e um sentimento que ao bom equilíbrio induz a pessoa ao estado de alerta físico necessário na natureza, na presença do stress nossa cérebro ordena ao nosso organismo a produção do hormônio de adrenalina acima no normal, nosso batimento cardíaco se acelera os músculos se tencionam, a pressão arterial sobe, as pupilas se dilatam e a própria química cerebral se altera, e muda três substâncias do sistema nervoso, a serotonina, a dopamina e a noradrenalina. Com todas essas mudanças no organismo as ações de qualquer colaborador mudam e se tornam mais rápidas e assertivas.

De acordo com o nível do stress, o organismo reage de uma maneira a trazer algo de bom para nosso dia-a-dia, o estágio de alerta é um fator essencial para que o colaborador mantenha-se atento e torna-se mais criativo, caso contrário o stress destina as pessoas ao esgotamento que coloca as mesmas em situações totalmente críticas, mas quando canalizadas esses emoções pode gerar soluções criativas para o stress.

Para prevenir o stress ou evitar que ele atinja níveis comprometedores, é importante, em primeiro lugar, saber reconhecer seus primeiros sinais tanto no corpo como na mente. Só podemos nos proteger de algo quando sabemos o que esse algo é que aparência tem como se manifesta e como é sua ausência. Sim, há pessoas tão cronicamente estressadas que não sabem o que é ficar sem a presença constante do stress, de tal modo que não saberiam reconhecer o que é estar bem. Por essa razão, antes de conhecer as técnicas de enfrentamento mais sofisticadas, deve-se entender todo o fenômeno do stress. (LIPP, 2014, p.108).

Contudo, quando se sabe o que realmente é o stress, se torna mais fácil o controle do mesmo podendo canalizar essas emoções e se sobressair de forma resiliente absorvendo algo positivo de determinada situação estressante, mesmo sabendo que o stress afeta diretamente na saúde do ser humano, é algo que sempre estará presente em nosso organismo, podendo ser usado em lados positivos ou acarretando em problemas futuros no ambiente organizacional e em nosso dia-a-dia.

Para Franca \& Rodrigues (2002), O stress é uma alteração em nosso organismo que deforma nossa capacidade de resposta imediata, podendo influenciar em nosso comportamento 
diário e afetivo, e algo que modifica ate mesmo nosso estado físico e nos forca a adaptarmos a alguma situação diante das organizações.

Contudo, quando se cita o termo stress e dizer que se pode chegar a dois extremos diante do mesmo, a criatividade, a atenção, o alerta é algo que beneficia em algo diante do dia-a-dia, como se pode atingir diante das organizações e presença de familiares a fase de resistência e logo em seguida a exaustão que afeta diretamente o organismo e leva-o a sérios e graves problemas como até a causa da morte.

Esta etapa do artigo aborda as principais fontes causadoras do stress no ambiente de trabalho e de que forma pode se controlar esses acontecimentos. O stress coloca dúvidas de onde pode ocasionar tanta tensão e pressão psicológica. Nessa parte do artigo trata-se de quais são as principais causas que afetam, diretamente, o trabalhador no ambiente organizacional.

O stress pode advir de fontes externas ou internas, da seguinte forma: Fontes Externas: desarmonia familiar, assalto, morte, má moradia, etc. Fontes Internas: dores, doenças, alteração químicas do organismo, tipo de personalidade, crenças, formas de interpretar o mundo. (SILVA, 2004, p.23).

Alguns dos aspectos citados mostram as causas que podem provocar traumas e até doenças devido aos acontecimentos vividos por diversas pessoas, e isso afeta diretamente na organização que depende da mão-de-obra de qualquer colaborador que está sujeito a vivenciar algo desse tipo.

Segundo Lipp (2010), o stress é representado com vários tipos de sentimentos, tais como: tristeza por ter perdido de grande valor seja tangível ou intangível, diminuindo a autoestima; a alegria por uma percepção ou expectativa de ganho, exemplo: um amor, bens, metas etc.; o medo que significa na percepção de ameaça iminente, a injuria física, doença, rejeição social, ameaça de desastre econômico perda de objetos valiosos, e pôr fim a raiva que demonstra o desequilíbrio que provoca ataques deliberado, físico, verbal, coerção, privação, oposição, invasão e atos que coloca como fontes de desequilíbrio e gera fortes fontes para que ocorram conflitos.

\section{DISCUSSÃO}

Portanto, o stress apresenta diversas causas para que ocorram variações no comportamento dos colaboradores na organização, tal comportamento que comprometem o rendimento e o andamento do processo produtivo. Para que isso seja amenizado, cabe aos líderes tomarem diversas providências para com tal problema.

"Sempre que um homem interage com outras pessoas ou com seu meio ambiente, cria-se certadose de stress. O stress, na verdade,é tão velho quanto à história da humanidade". (SILVA, 2004, p. 24).

No entanto, a dosagem de stress vivenciada no dia-a-dia nas organizações é gerada pelos tipos de relacionamentos e convivência das pessoas que é algo normal no cotidiano de qualquer colaborador, caso o stress seja em excesso deverá causar algumas consequências.

Escolhi estender ao campo do trabalho este estudo do estresse, pois é este o campo do fazer humano necessário, do qual muito poucos conseguem escapar. O trabalho, ao mesmo tempo em que é uma conquista. Traz para quem trabalha o germe do seu desgaste. $O$ trabalho supõe relações e laços sociais. (ARANTES e VIEIRA, 2006, p. 85).

O stress vem de todas as atividades que traz o convívio diário nas organizações e coloca o colaborador no ambiente de trabalho em uma fase de alerta, e gera para a organização 
aspectospositivos para seu funcionamento, diante de tantas adversidades no cotidiano de cada colaborador o stress transmite estado de alerta até certo ponto, ao ultrapassar tal ponto o stress pode trazer sérios problemas de saúde que poderá causar afastamento do colaborador, casos que acontecem com frequência atualmente nas organizações.

Na situação particular, do stress relacionado ao trabalho, ele é definido como as situações em que a pessoa percebe seu ambiente de trabalho como ameaçador a suas necessidades de realização pessoal e profissional e/ou a sua saúde físicaou mental, prejudicando a interação desta com o trabalho e com o ambiente de trabalho,à medida que esse ambiente contem demandas excessivas a ela, ou que ela não contem recursos adequados para enfrentar tais situações. (FRANCA \& RODRIGUES, 2002, p.34)

A partir do momento em que o colaborador percebe o ambiente de trabalho ameaçador, isto são sinais vitais de stress e que afeta diretamente ao longo dos estágios em que se encontram para o colaborador é necessário ter o sentimento de conforto e estar à vontade no ambiente organizacional para que seja filtrado somente algo que possa gerar resultados positivos.

\section{CONCLUSÃO}

O mercado atual é, altamente, competitivo e as empresas devem utilizar seus recursos de maneira totalmente proveitosa. Nesse ponto, o recurso humano se apresenta como a principal ferramenta para ser um diferencial na competição mercadológica, e as empresas pode desenvolver ou frear esta capacidade dos indivíduos que estão convolutos no processo; observando que muitas outras características vinculadas a natureza da empresa conflitam com as divergências de interesses individuais, resultando em uma mudança no comportamento da organização.

Assim, em todas as empresas estas características se materializam em fontes de estresse e estas provocações conhecidos como estressores, resultam em desapontamento e ansiedade, ocorrendo variações de intensidade entre os indivíduos.

O estudo do estresse e sua vinculação com a qualidade de vida tem sido um estudo que cresce atualmente, não somente na questão familiar, como, também, nas relações de trabalho. No trabalho, o estresse é um assunto que atrai interesse, porém o mesmo gera contrassensos.

Por meio dessa instigação do estresse dentro da execução do trabalho, o assunto é atrativo, assim como tem provocado o interesse de outros pesquisadores, muito relacionado também ao choque causado pelo estresse na saúde dos indivíduos dentro de uma organização, resultando insuficiência na produção e no potencial real do trabalhador.

No contexto pessoal, o estresse pode ser um estimulante à mudança após a reação a algum fato, porém no âmbito organizacional, o gerenciamento errôneo pode se tornar problemático e trazer negativismo em setores produtivos, transformando em doenças e sobrecargas na execução de determinadas tarefas, consequentemente, afeta a qualidade e o desenvolvimento do trabalho.

A pesquisa demonstrou que os agentes que possuem maior influência no estresse dentro das organizações estão relacionados a sobrecarga de tarefas a realizar, cobranças e pressão no trabalho, liderança inexistente ou inadequada, falta de reconhecimento, metas frequentes, e o mau relacionamento.

Quando o relacionamento não é adequado o resultado são conflitos, e estes conflitos não sendo gerenciados resultam em uma desordem emocional e produtiva da organização, sendo que quando acumulado e solto gera comportamentos que não são adequados a um espaço de trabalho. Todo esse conflito gera no ambiente um desconforto, ocasionado pelo não gerenciamento correto ou autoridade necessária frente aos conflitos no local de trabalho.

Sendo assim, não há uma forma de combater o estresse, pois ele se evidencia de maneiras diferentes em cada indivíduo, deste modo cada um deve produzir uma forma de manter e reverter 
este processo de estresse e vincular atitudes como controle e conscientização, para proporcionar valores de proteção e desenvolvimento para si próprio, aliado a táticas gerenciais do administrador a fim de reverter este estresse.

Compreende-se que o estresse nunca deixará de existir, entretanto podem ser tomadas medidas para que a sua apresentação seja menos expressiva nas organizações. Cada indivíduo e a organização devem buscar formas em que a realização do trabalho seja prioridade e assim possibilitar a realização das metas, onde o gestor assegura a motivação dos colaboradores e proporciona recursos para os trabalhadores realizarem seus trabalhos, resultando em um ambiente de trabalho favorável e proporcional em busca de resultados.

\section{REFERÊNCIAS BIBLIOGRÁFICAS}

ARANTES, M. A. C. e VIEIRA, M. J.F.,Estresse Clínica Psicanalítica, $3^{\circ}$ Ed. Casapsi Livraria, Itatiba, 2006.

ARROBA, T. e J, K.,Pressão no trabalho Stress: um Guia de sobrevivência. Ed. McGraw-Hill, Porto Alegre, 1988.

CARMELLO, E.,Resiliência: A transformação como ferramenta para construir empresas de valor. Ed. Gente, São Paulo, 2008.

CHIAVEnAto, A., Gestão de Pessoas. Ed. Elsevier, São Paulo 2010.

FRANÇA, A. C. L., RODRIGUES, A. L., Stress e trabalho: uma abordagem psicossomática. Ed. Atlas, São Paulo, 2002.

LIPP, M E. N., Stress e o turbilhão da raiva. Ed. Casapsi Livraria, Itatiba, 2010.

LIPP, M E. N., Stress e o turbilhão da raiva. Ed. Casapsi Livraria, Itatiba, 2005.

LIPP, M. E. N., Mecanismos Neuropsicofisiológicos do stress: teorias e aplicações clinicas. $3^{\circ}$ Ed. Casapsi Livraria, Itatiba, 2010.

LIPP, M. E. N., O stress do Professor. Ed. Papirus, 2014.

MARTINELLI, D. P.,Negociação Empresarial: Enfoque sistêmico e visão estratégica. Ed. Manole Ltda. São Paulo 2002.

MATTOS, G. G., Comunicação Empresarial sem Complicação, Ed. Manole Ltda. São Paulo 2009.

PEREIRA. A. M. T. B., Quando o trabalho ameaça a bem estar do trabalhador. Ed. Casa do psicólogo, 201

PIOVAM, R., Resiliência: como superar pressões e adversidades no trabalho. Ed. Reino Editorial, São Paulo, 2009.

ROBBINS, S. P., Fundamentos do comportamento organizacional. Ed Pearson Prentice Hall, São Paulo, 2004. 
SILVA, J, J.,Stress o impulso da vida. Ed. Midiograf, Londrina, 2004. 